\title{
ASSESSMENT OF FARMERS AWARENESS ON THE ENVIRONMENTAL EFFECT AND SAFETY IMPLICATIONS OF AGRO-CHEMICALS: A STUDY OF RICE FARMERS IN ABEOKUTA
}

\section{Rosiji Comfort Oluseyi ${ }^{1}$ and Olukayode Oluwakemi Omolara ${ }^{2}$}

\author{
${ }^{1}$ Department of Environmental Health Sciences/School of Environment and Public \\ Health/Ogun State College of Health Technology, Ilese Ijebu, Ogun, Nigeria. \\ Email: comfortseyi@yahoo.com
}
${ }^{2}$ Department of Water and Sanitation Technology/School of Specialized Health and Medical Technicians/Ogun State College of Health Technology, Ilese Ijebu, Ogun, Nigeria. Email: Kemi4jesus2011@gmail.com

\begin{abstract}
Cite this article:
Rosiji C.O., Olukayode O.O. (2021), Assessment of Farmers Awareness on the Environmental Effect and Safety Implications of AgroChemicals: A Study of Rice Farmers in Abeokuta. African Journal of Environment and Natural Science Research 4(3), 59-70. DOI: 10.52589/AJENSRY1XRUW8C.
\end{abstract}

\section{Manuscript History}

Received: 28 March 2021

Accepted: 21 April 2021

Published: 24 July 2021

Copyright $\odot 2020$ The Author(s). This is an Open Access article distributed under the terms of Creative Commons AttributionNonCommercial-NoDerivatives 4.0 International (CC BY-NC-ND 4.0), which permits anyone to share, use, reproduce and redistribute in any medium, provided the original author and source are credited.
ABSTRACT: This study assessed farmer's awareness of the environmental effect and safety implications of agrochemicals (A study of rice farmers in Abeokuta, Ogun State. Agrochemicals are pesticides, herbicides, or fertilizers used for the management of ecosystems in agricultural sectors. Rudimentary variations on agrochemicals have been used for millennia to improve crop yields and control the populations of agricultural pests. The study is a descriptive survey; in which 15 questionnaires were formulated and distributed to the farmers in Abeokuta, Ogun using stratified sampling techniques. The result of the study showed that $73 \%$ of the respondents know that Agrochemicals are chemicals (pesticides and fertilizers) used to boost agricultural production while $27 \%$ did not. Also, $87 \%$ are aware of the environmental effect of agro-chemical used in the farm while $13 \%$ are not. 67\% know that Agrochemical mishandling constitutes one of the most severe farm operation hazards confronting farmers, their produce, and the environment while $33 \%$ did not. And $93 \%$ has ever attended any seminar/workshop on how to use agrochemicals on crops and rice productions while $7 \%$ stated otherwise. Also, $16 \%$ of the respondents stated that they have ever encountered any problem in the last two years while $84 \%$ stated otherwise. Moreover, 9 of them are properly informed of the risks and precautions involved in the application of toxic chemicals on the rice Productions while 6 disagreed with that. Furthermore, $47 \%$ of the respondents are exposed to agrochemicals during applications while 53\% disagreed with that and lastly, $80 \%$ usually wear protective materials whenever they're on the farm while $20 \%$ stated otherwise. However, pesticides continue to be a significant and growing component of modern rice technology. The relative importance of pesticides has increased despite the availability of alternatives to exclusive chemical pest control such as varietal resistance and integrated pest management (IPM). Despite the benefits involved in the use of agrochemicals, there are also health and environmental problems associated with its use. However, the farmers' knowledge of the use of agrochemicals in Nigeria has been fraught with problems. Therefore, the protection of our crop through the control of pest and disease agents can make a major contribution towards increased agricultural productivity, the standard of living of rural community dwellers and national development.

KEYWORDS: Farmers Awareness, Environmental Effect, Rice Farmers, Safety Implications, Agro-Chemicals. 


\section{INTRODUCTION}

\section{Background of the Study}

Agriculture (crop production and animal husbandry) is the core of the economy and the largest employer of labour and contributes up to $50 \%$ of the National Gross Domestic Product (GDP) (MAFS, 2012). In developing countries of the world including Nigeria, rapid human population growth is experienced. This increase in human population goes along with increased food demand. Man was able to coax high productivity through the breeding and management of food, plants and animals through knowledge and technology in order to meet the demand for food.

Agrochemical refers to the broad range of pesticide including insecticide, herbicides and fungicides. It also included specialized nutrient product such as organic chalets of iron and manganese aimed at curbing deficiencies "disease of plants" and those chemical compounds having some other uses as the encouragement of rooting of cutting or off setting of fruits. It may also include synthetic fertilizers, hormones and other chemical growth agents and concentrated stores of raw animal manure (Larry 2012).

The term- agrochemicals is very broad to include all chemical products intended for use in prevention and control of pests and diseases as well as weeds in crop or chemical products used to protect harvested products against pest and diseases or chemical products used to eradicate mosquitoes or ticks of cattle and other acaricides (Wilma, Arendse and Jennes, Aragones 2019).

Agrochemicals (pesticides and fertilizers) are looked upon as a vehicle for improved crop production technology, though it is a costly input. Balance use, optimum doses, correct method and right time application of agrochemicals ensures increased crop production (Govinda Bhandari 2014). Most agrochemicals are toxic and all agrochemicals in bulk storage and on use pose significant environmental and/or health risk mostly in the event of accidental spills. This may be a good reflection of the situation in Nigeria where the risk associated with health and the environment are reportedly caused by the farmer's lack of knowledge on how to use the agrochemicals and the required skill for effective use. According to Ohaji (2014), it has been observed that the response of small-scale farmers to the use of such pesticides continue to decrease per year.

Some of the reasons adduced are perceived high cost of pesticides and poor financial position of most small-scale farmers, lack of awareness on the benefits of pesticides, lack of knowledge on proper and safe application methods, non-availability and inaccessibility of pesticides as well as misinformation on the health risk of pesticides. Safety and health in the use of agrochemicals have been one of the primary concerns of international organizations and of many governments, employers and workers and their organizations for over two decades ILO (2011).

\section{Statement of the Problem}

The major problem the agricultural sector is facing today is the great loss of its products. These losses are a result of pests, weeds and disease attack. The use of agrochemical has however substantially helped to reduce the risk of yield losses and has contributed to increasing agricultural productivity. Inorganic fertilizer seems to be one of the practical ways to provide 
enough plant nutrients to restore Africa's nutrient-depleted soils and feed Africa's human population (Ahemba 2009). Despite the benefits involved in the use of agrochemicals, there are also health and environmental problems associated with its use. However, the farmers' knowledge of the use of agrochemicals in Nigeria has been fraught with problems.

In the developed countries, issues related to the use of agrochemicals to improve agricultural productivity have been properly addressed and this has also helped to minimize the hazardous effects involved in the misuse of these agrochemicals to a bearable level. Whereas in most developing countries, much publicity has not been made to enlighten the public on the implication of the misuse of agrochemicals, its health and environment associated risk. Therefore, this study is aimed to assess the farmer's awareness of the environmental effect and safety implications of agrochemical use on rice (A case Study of rice farmers in Abeokuta, Area of Ogun State).

\section{Objectives of the Study}

To assess the farmer's awareness of the environmental effect and safety implications of agrochemical use on rice (A case Study of rice farmers in Abeokuta, Area of Ogun State)

\section{Specific Objective of the Study}

i. To investigate the knowledge, attitude and practice of rice farmers towards agrochemical use in rice farming.

ii. To determine the environmental effect of agrochemical use on rice farming.

iii. To know the safety implications

\section{Research Question}

i. What are the knowledge, attitude and practice of rice farmers towards agrochemical use in rice farming?

ii. What are the environmental effects of agrochemical use in rice farming?

\section{Research Hypotheses}

i. Knowledge, attitude and practice (KAPS) of rice farmers towards agrochemical use in rice farming is significantly low.

ii. There is a significant relationship between the environmental effects of agrochemical use and rice farmers?

\section{Significance of the Study}

The nation will benefit in as much as the study will help to fish out the problems involved in the use of agrochemicals and other raw materials to the farmers. This will serve as a base for government and policymakers to develop new programmes or make the necessary adjustment to the existing ones for increased food and raw material production. In developing countries such as Nigeria, the food supply is inadequate and the quality of food produced is highly deteriorating due to poor agricultural technology, wrong use of agrochemicals, poor funding, crop infestation, weeds and pest attack. 
Therefore, the protection of our crops through the control of pest and disease agents can make a major contribution towards increased agricultural productivity, standard of living of rural community dwellers and national development. Furthermore, farmers will benefit from this study by using the recommendations which this study will provide to know how to use the agrochemicals and the necessary related precautionary measures to be considered to reduce the health and environmental risk involved.

\section{LITERATURE REVIEW}

The use of agrochemicals, particularly pesticides, has become an integral part of Nigerian agricultural activities, being used on cash crops, cereals, fruits, and vegetable production. Dinham (2011) reported that about $87 \%$ of vegetable farmers use chemical pesticides to control pests and diseases.

The Pesticides Control and Management Act (528) was promulgated in 1996 to regulate the proper use of pesticides in Ghana. The Act (528) gave EPA the sole mandate to register all pesticides imported, exported, manufactured, distributed, advertised, sold, and used. The act, divided into four parts, comprises regulation of pesticides, licensing of pesticide dealers, enforcement of penalties on defaulters, and general provisions (Dinham 2011).

According to Horna et al. (2018), the use of pesticides by farmers to control weeds, increase agricultural productivity, and preserve agricultural produce is on the increase daily, thereby calling for urgent attention.

According to Okoffo et al. (2016), the inappropriate use of pesticides to control pests and diseases has major health implications for smallholder farmers and this is now on the global scale attracting the global attention of researchers, policymakers, and the general public (consumers). Improper use and disposal of containers of pesticide are mainly caused by inadequate knowledge, inadequate equipment and storage, application of unregistered and nonapproved pesticides, and the use of excessive dosage.

Larry 2012, in a research carried out on maize plant stated that overdose and too much exposure of maize plant to agrochemicals cause scorches, yellowing, necrosis of the foliage, and distortions of the leaves. In this instance, a higher rate of application has the potency to affect maize output level. Residues of agrochemicals sometimes remain in maize edible parts which have a health impact on the consumer.

Dinham 2013, revealed from research carried out that, manufacturers of agrochemicals exploit several methods such as graph, labels, and pictures to raise concrete awareness to the users about the health risks associated with their use of the products. Government agencies (Ministry of Food and Agriculture, Standard Board and Environmental Protection Agency) and Nongovernmental Organizations (NGO's) have also not relented in their efforts in making farmers more aware of the health implications of agrochemical use. Meanwhile, the achievable targets have not been reached. This means that certain socioeconomic and demographic factors influence certain socioeconomic and demographic factors influence the farmer's awareness level of health implications of agrochemical use. 
Lichtenberg et. al., 2016 also stated the need to further provide information to policymakers and agricultural extension officers to come out with effective training programs for farmers for them to know the various health risks associated with agrochemical use. Hence, such information could be used by the Ministry of Agriculture, agrochemical companies, and other agencies to raise awareness of the need for safe handling and use of agrochemicals by farmers.

\section{MATERIALS AND METHODS}

\section{Research Design}

This research work is a descriptive research design, it employed the use of structured questionnaires administered to the respondents (farmers) within the study area. According to WHO, 1978's descriptive research involves collecting data in order to test the hypothesis or to answer the research question about the subject of study. It was ensured that during the field survey, the questionnaires are being interpreted into the language the farmers speak.

\section{Description of the Study Area}

This study was carried out among rice farmers in Abeokuta, Ogun, Southwestern Nigeria. Abeokuta is the state capital of Ogun State having the coordinate of. It is situated on the east bank of the Ogun River, near a group of rocky outcrops in a wooded savanna; 77 kilometres (48 mi) north of Lagos by railway, or 130 kilometers by water. The Study Area is accessible by major and minor road network.

\section{Sample Size and Sampling Technique}

The sampling consists of a total number of fifteen (15) respondents who were randomly selected among the rice farmers in Abeokuta, Ogun State using stratified random techniques. The sampling was to give every respondent an equal chance of being selected.

\section{Data Collection}

The materials used for this investigation are mainly questionnaires, sometimes complemented by oral questions, observation and explanation.

The respondents were given the appropriate questionnaires to fill and these were collected after completion or whenever necessary. Thereafter, the questionnaires were collated and the data analyzed and interpreted.

\section{Validity and Reliability}

The draft of the questionnaire was examined by the researcher's supervisor who ensured that questionnaire items are structured in such a way that the variables in the study are covered and elicited the expected response.

To ensure outright reliability of the instrument, a pre-test will be done by administering the instrument to some respondents who are not part of the study in order to ascertain the reliability of the instrument. 


\section{Method of Data Collection}

The self-designed questionnaires were administered to the respondents and retrieved back as soon as they finished attempting the questions. The researcher personally administered the questionnaires to the respondents so as to clarify the purpose of the questionnaires and direct them on how to attempt the questions.

\section{Data Analysis}

The completed questionnaires were collected and analyzed using both descriptive and inferential statistics. Descriptive statistics of frequency distribution counts and percentages were used while the inferential statistics of chi-square $\left(\mathrm{X}^{2}\right)$ was also used to test the hypotheses at a 0.05 level of significance.

\section{PRESENTATION AND ANALYSIS OF DATA}

\section{Demographic Aspect Of Data}

The demographic aspect of the questionnaire which deals with facts such as sex, educational qualification, occupational status as well as religion and age of correspondent to the questionnaire is clearly stated in Table 1

Table 4.1: Showing the Demographic Bio-data of Correspondent

\begin{tabular}{|l|l|l|l|}
\hline DEMOGRAPHIC & VARIABLES & VARIABLES & VARIABLES \\
\hline Sex & Male (14) & Female (1) & \\
\hline Educational qualification & Primary (8) & Secondary (6) & Tertiary (1) \\
\hline Marital status & single (3) & Married (12) & Divorced (0) \\
\hline Religion & Christianity (7) & Islamic (6) & Tradition (2) \\
\hline Age & $18-25(2)$ & $26-30(10)$ & 31 and above (3) \\
\hline
\end{tabular}

From table 1 above, of the fifteen (15) correspondents that were administered with the questionnaire, fourteen of them are males while the remaining 1 is a female. In terms of educational background, eight of them had primary education as their last academic pursuit as six (6) of them possess secondary education while the remaining respondent (1) has an advanced tertiary level education. Concerning the religion of correspondents, seven (7) of them were Christianity, six (6) were practising Islam while only two (2) indicated traditional religion. In respect to the age bracket of correspondent, most of them are within the age bracket 2630 years with ten (10) correspondents closely followed by the age bracket of 31 years and above with two of them belonging to the $18-25$ years. 


\section{Analysis of Research Hypothesis}

Research Hypothesis 1: Knowledge, attitude and practice (KAPS) of rice farmers towards agrochemical use on rice farming is significantly low.

Each correspondent was required to answer four (4) well-structured questions which were used to access the farmers' awareness of the environmental effect and safety implications of agrochemical ranging from Yes ( ) No ( )

Table 4.2: Knowledge of the respondents on the environmental effect and safety implications of agrochemical on rice farmers

\begin{tabular}{|l|l|l|l|l|l|}
\hline Questions & Yes & \% & No & \% & TOTAL \\
\hline $\begin{array}{l}\text { Do you know that Agrochemicals are } \\
\text { chemicals (pesticides and fertilizers) } \\
\text { used to boost agricultural } \\
\text { production? }\end{array}$ & 11 & 73 & 4 & 27 & 100 \\
\hline $\begin{array}{l}\text { Are you aware of the environmental } \\
\text { effect of agrochemical used on the } \\
\text { farm? }\end{array}$ & 13 & 87 & 2 & 13 & 100 \\
\hline $\begin{array}{l}\text { Have you ever attended any } \\
\text { seminar/workshop on how to use } \\
\text { agrochemicals on crops and rice } \\
\text { productions? }\end{array}$ & 10 & 67 & 5 & 33 & 100 \\
\hline $\begin{array}{l}\text { Do you know that Agrochemical } \\
\text { mishandling constitutes one of the } \\
\text { most several farm operation hazards } \\
\text { confronting farmers, their produce, } \\
\text { and the environment }\end{array}$ & 14 & 93 & 1 & 7 & 100 \\
\hline
\end{tabular}

Question 1 assessed the knowledge of the respondents on the environmental effect and safety implications of agrochemical on rice farmers. $73 \%$ of the respondents know that agrochemicals are chemicals (pesticides and fertilizers) used to boost agricultural production while $27 \%$ did not. Also, $87 \%$ are aware of the environmental effect of agro-chemical used in the farm while $13 \%$ are not. $67 \%$ know that agrochemical mishandling constitutes one of the most several farm operation hazards confronting farmers, their produce, and the environment while $33 \%$ did not. And $93 \%$ have ever attended any seminar/workshop on how to use agrochemicals on crops and rice productions while $7 \%$ stated otherwise. 
Table 4.2.1: Attitude of the respondents towards agrochemical use on rice farming

\begin{tabular}{|l|l|l|l|l|l|}
\hline Questions & Yes & $\%$ & No & $\%$ & TOTAL \\
\hline $\begin{array}{l}\text { Have you ever encountered any problem in the last } \\
\text { two years? }\end{array}$ & 8 & 53 & 7 & 43 & 100 \\
\hline $\begin{array}{l}\text { Are you properly informed of the risks and } \\
\text { precautions involved in the application of toxic } \\
\text { chemicals on rice Productions? }\end{array}$ & 9 & 60 & 6 & 40 & 100 \\
\hline $\begin{array}{l}\text { Have you ever exposed to agro-chemical during } \\
\text { applications? }\end{array}$ & 7 & 47 & 8 & 53 & 100 \\
\hline $\begin{array}{l}\text { Do you usually wear any protective materials } \\
\text { whenever you in the farm? }\end{array}$ & 12 & 80 & 3 & 20 & 100 \\
\hline
\end{tabular}

From the table above it was deduced that $16 \%$ of the respondents stated that they have ever encountered any problem in the last two years while $84 \%$ stated otherwise. Moreover, 9 of them are properly informed of the risks and precautions involved in the application of toxic chemicals on the rice Productions while 6 disagreed with that. Furthermore, $47 \%$ of the respondents are exposed to agro-chemical during applications while 53\% disagreed with that and lastly, $80 \%$ usually wear protective materials whenever they're on the farm while $20 \%$ stated otherwise.

Table 4.2.2: Practice of the respondents towards agrochemical use on rice farming

\begin{tabular}{|l|l|l|l|l|c|}
\hline Questions & Yes & $\%$ & No & \% & Total \\
\hline $\begin{array}{l}\text { Do you always wear shoes on the farm to } \\
\text { protect your feet? }\end{array}$ & 12 & 80 & 3 & 20 & 100 \\
\hline $\begin{array}{l}\text { Do you always protect your eyes with } \\
\text { goggles when spraying with } \\
\text { agrochemicals? }\end{array}$ & 10 & 67 & 5 & 33 & 100 \\
\hline $\begin{array}{l}\text { Do you always wear a respiratory device } \\
\text { when handling harmful chemical or } \\
\text { materials? }\end{array}$ & 8 & 53 & 7 & 47 & 100 \\
\hline $\begin{array}{l}\text { Do you normally read Chemical } \\
\text { Instruction before Used? }\end{array}$ & $\begin{array}{l}\text { Able to } \\
\text { Read } \\
(9)\end{array}$ & 60 & $\begin{array}{l}\text { Unable } \\
\text { To } \\
\text { Read } \\
(6)\end{array}$ & 40 & 100 \\
\hline
\end{tabular}


Table 4.2.3: Shows t-test analysis of the above research hypotheses

\begin{tabular}{|l|l|l|l|l|l|l|}
\hline AREA & SAMPLE SIZE & X & SD & DF & T.C & $\begin{array}{l}\text { Critical } \\
\text { value }\end{array}$ \\
\hline HIGH & 12 & 2.27 & 2.8 & 64 & 0.24 & 1.96 \\
\hline LOW & 03 & 2.1 & 2.76 & 0.56 & 0.24 & 1.96 \\
\hline
\end{tabular}

The above table shows that the calculated value of 0.24 is less than the critical value of 1.960 at a 0.05 level of significance.

Therefore, we fail to reject null and conclude that there is significant knowledge of the respondents on the environmental effect and safety implications of agrochemicals on rice farmers

\section{Hypothesis II: There is a significant relationship between the environmental effect of agrochemical use and rice farmers?}

\begin{tabular}{|l|l|l|l|l|c|}
\hline Questions & Yes & \% & No & \% & Total \\
\hline $\begin{array}{l}\text { Do you know that the inappropriate use of } \\
\text { pesticides to control pests and diseases has } \\
\text { major health implications on rice farmers? }\end{array}$ & 11 & 73 & 4 & 27 & 100 \\
\hline $\begin{array}{l}\text { Do you always protect your eyes with } \\
\text { goggles when spraying with agrochemicals? }\end{array}$ & 5 & 33 & 10 & 67 & 100 \\
\hline $\begin{array}{l}\text { Do you know that some agrochemicals are } \\
\text { extremely hazardous to the health of } \\
\text { workers and the general public, and also to } \\
\text { the environment }\end{array}$ & 87 & 2 & 13 & 100 \\
\hline $\begin{array}{l}\text { Do you know that the exposure of farmers } \\
\text { to agrochemicals has short term and long } \\
\text { term effects? }\end{array}$ & 10 & 67 & 5 & 33 & 100 \\
\hline
\end{tabular}

In response to the question, 73 of the respondents know that inappropriate use of pesticides to control pests and diseases has major health implications on rice farmers while 27 do not. Also, $33 \%$ said they always protect their eyes with goggles when spraying with agrochemicals while $67 \%$ do not. Moreover, $87 \%$ know that some agrochemicals are extremely hazardous to the health of workers and the general public and also to the environment while $13 \%$ do not know. Finally, $67 \%$ are aware that exposure of farmers to agrochemicals has short term and long term effect, $33 \%$ are not. 


\begin{tabular}{|l|l|l|l|l|l|l|}
\hline $\begin{array}{c}\text { Test for } \\
\text { research } \\
\text { question }\end{array}$ & SAMPLE SIZE & $X$ & SD & DF & T.C & $\begin{array}{l}\text { Critical } \\
\text { value }\end{array}$ \\
\hline HIGH & 15 & $\mathbf{2 . 2 3}$ & $\mathbf{2 . 6 2}$ & $\mathbf{5 8}$ & $\mathbf{- 0 . 2 1}$ & $\mathbf{1 . 9 6}$ \\
\hline LOW & 15 & 2.38 & $\mathbf{2 . 8 7}$ & $\mathbf{5 8}$ & $\mathbf{- 0 . 2 1}$ & $\mathbf{1 . 9 6}$ \\
\hline
\end{tabular}

The above table shows that the calculated value of -0.21 is less than the critical value of 1.960 at 0.05 level; of significance.

Therefore, we fail to reject the null hypothesis and conclude that there is no significant relationship between the environmental effect of agrochemical use and rice farmers.

\section{DISCUSSION OF FINDINGS}

Fifteen (15) correspondents were administered with the questionnaire, of the fifteen (15) correspondents who were administered with the questionnaire, fourteen of them are males while the remaining 1 is a female. In terms of educational background, eight of them had primary education as their last academic pursuit, six (6) of them possess secondary education while remaining respondents (1) one has an advanced education of tertiary level. Concerning the religion of the correspondents, seven (7) of them were Christians, six (6) were practising Islam while only two (2) indicated traditional religion. In respect to the age bracket of correspondent, most of them are within the age bracket 26-30years with ten (10) correspondents closely followed by the age bracket of 31years and above with two of them belonging to the $18-25$ years.

\section{Analysis of Research One}

Question 1 assessed the knowledge of the respondents on the environmental effect and safety implications of agrochemicals on rice farmers. Knowledge of the respondents on the environmental effect and safety implications of agrochemicals on rice farmers. $73 \%$ of the respondents know that Agrochemicals are chemicals (pesticides and fertilizers) used to boost agricultural production while $27 \%$ did not. Also, $87 \%$ are aware of the environmental effect of agrochemicals used on the farm while 13\% are not. 67\% know that Agrochemical mishandling constitutes one of the most severe farm operation hazards confronting farmers, their produce, and the environment while 33\% did not. And 93\% have ever attended any seminar/workshop on how to use agrochemicals on crops and rice productions while $7 \%$ stated otherwise. From the hypothesis tested, it is concluded that there is significant knowledge of the respondents on the environmental effect and safety implications of agrochemicals on rice farmers. This is in line with [Gill, 2014] who stated that farmers have adopted some strategies in the bid to increase the productivity of crops. These are: intensive use of land, agrochemical usage, irrigation, disease and pest-resistant varieties, and so forth. Farmers are highly motivated to use these strategies due to the emphasis placed by most agricultural development policies which suggest the use of external inputs such as machinery and agrochemicals as the panacea to increasing food productivity and has led to increasing the use of synthetic agrochemicals instead of the biological, cultural, and mechanical method for boosting production, controlling pest, weed, and disease. 


\section{Research Question II}

it was deduced that $16 \%$ of the respondents stated that they have ever encountered any problem in the last two years while $84 \%$ stated otherwise. Moreover, 9 of them are properly informed of the risks and precautions involved in the application of toxic chemicals on the rice Productions while 6 disagreed with that. Furthermore, $47 \%$ of the respondents are exposed to agro-chemical during applications while 53\% disagreed with that and lastly, $80 \%$ usually wear protective materials whenever they're on the farm while $20 \%$ stated otherwise. Therefore, we fail to reject the null hypothesis and conclude that there is no perceived attitude of the respondents on the environmental effect and safety implications of agrochemicals on rice farmers.

\section{Research Question III}

In response to the question, 73 of the respondents know that the inappropriate use of pesticides to control pests and diseases has major health implications on rice farmers while 27 do not. Also, $33 \%$ said they always protect their eyes with goggles when spraying with agrochemicals while $67 \%$ do not. Moreover, $87 \%$ know that some agrochemicals are extremely hazardous to the health of workers and the general public, and also to the environment while $13 \%$ do not know and finally, $67 \%$ are aware that exposure of farmers to agrochemicals has short term and long-term effect 33\% are not. This, in line with ((Larry 2012) who stated that the ability to apply the right quantity is dependent on awareness of the health implications and the physiological effect on crop output and the quality of the produce. Agrochemicals affect maize crops directly. Overdose and too much exposure of maize plants to agrochemicals cause scorches, yellowing, necrosis of the foliage, and distortions of the leaves. In this instance, a higher rate of application has the potency to affect maize output level. Residues of agrochemicals sometimes remain in maize edible parts which have a health impact on the consumer.

\section{SUMMARY AND CONCLUSION}

In summary, this study assessed farmer's awareness of the environmental effect and safety implications of agro-chemicals on farm produce. Rice farmers in Abeokuta, Ogun State were used for this research. The study is a descriptive survey; in which 15 questionnaires were formulated and distributed to the farmers in Abeokuta, Ogun State using stratified sampling techniques. From the result obtained from the field research, it is revealed that pesticides continue to be a significant and growing component of modern rice technology. The relative importance of pesticides has increased despite the availability of alternatives to exclusive chemical pest control such as varietal resistance and integrated pest management (IPM). Despite the benefits involved in the use of agrochemicals, there are also health and environmental problems associated with its use. However, the farmers' knowledge of the use of agrochemicals in Nigeria has been fraught with problems. Therefore, the protection of our crops through the control of pest and disease agents can make a major contribution towards increased agricultural productivity, standard of living of rural community dwellers and national development. 
Conclusively, the relative importance of pesticides has increased despite the availability of alternatives to exclusive chemical pest control such as varietal resistance and integrated pest management (IPM). Despite the benefits involved in the use of agrochemicals, there are also health and environmental problems associated with its use. However, the farmers' knowledge of the use of agrochemicals in Nigeria has been fraught with problems. Therefore, the protection of our crop through the control of pest and disease agents can make a major contribution towards increased agricultural productivity, standard of living of rural community dwellers and national development.

\section{RECOMMENDATIONS}

i. Government should promote healthy production and storage of rice by enlightening and educating the farmers on the effect of using agrochemicals.

ii. Farmers should be given adequate knowledge and information on the health hazards associated with handling and use of agrochemicals

iii. Policymakers and agricultural extension officers should help with effective training programs for farmers on a regular basis in order to checkmate their activities.

iv. Rice farmers should read the instructions on the label of the chemical used before usage

v. Rice farmers in Nigeria need to be educated so as to know the effects of pesticide residue on the rice and consumers

vi. Regulation of appropriate chemicals that the farmers can use on their farm produce should be issued by the government to the farmers and ensure their enforcement. 